\title{
Оценка внутривидовой изменчивости анатомо-морфологических параметров хвои Juniperus communis L.
}

\section{Assessment of intraspecific variation of anatomical and morphological parameters of needles of Juniperus communis L.}

\author{
Князева С. Г. ${ }^{1}$, Хантемирова Е. В. ${ }^{2}$ \\ Knyazeva S. G. ${ }^{1}$, Hantemirova E. V. ${ }^{2}$ \\ ${ }^{1}$ Институт леса им. В. Н. Сукачева СО РАН, г. Красноярск, Россия. E-mail: knyazevas@mail.ru \\ ${ }^{2}$ Институт экологии растений и животных Уральского отделения Российской академии наук, Екатеринбург, Россия. \\ E-mail: hantemirova@mail.ru \\ ${ }^{1}$ Sukachev Institute of Forest SB RAS, Krasnoyarsk, Russia \\ ${ }^{2}$ Institute of plant and animal ecology UB RAS, Ekaterinburg, Russia
}

\begin{abstract}
Peфepam. Нами проводилось исследование анатомо-морфологической изменчивости параметров хвои 25 природных популяций Juniperus communis L., произрастающих на территории Европы, Азии и Северной Америки. Исследование показало, что кавказские популяции по всем признакам отличаются от остальных и, вероятно, кавказский можжевельник представляет собой отдельный вид или разновидность. Переходной оказалась популяция из Сочи, которая по ряду параметров близка к альпийским растениям, относящимся к J. communis var. saxatilis. Дальневосточные популяции характеризуются рядом общих черт в строении хвои (длинная, но короткая хвоя с одной устьичной полосой и крупными смоляными ходами), позволяющих считать их типичной формой $J$. communis var. saxatilis. Североамериканская популяция по всем изученным признакам не отличается от дальневосточных популяций и, скорее всего, является американской формой J. communis var. saxatilis. Сибирские и европейские популяции составляют единую группу, где у каждой популяции в разной степени проявляются признаки как J. communis var. saxatilis, так и J.communis var.communis. Исключением являются Таллинская и Томская популяции, отличающиеся длинной и узкой хвоей и жизненной формой в виде дерева и, вероятно, являющиеся типичной формой можжевельника обыкновенного - J.communis var.communis. Наиболее информативными признаками для целей разделения таксонов являются длина и ширина хвои, число полосок и Ка, анатомические признаки оказались менее информативными.
\end{abstract}

Ключевые слова. Анатомия, внутривидовая систематика, изменчивость, можжевельник обыкновенный, морфология.

Summary. We conducted a study of anatomical and morphological variability of needle's parameters in 25 natural populations of Juniperus communis L., growing in Europe, Asia and North America. The study showed that the Caucasian populations differ from the others by all features and probably the Caucasian juniper is a separate species or variety. Sochi population by a number of parameters is close to Alpine plants belonging to J. communis var. saxatilis. Far Eastern populations are characterized by a number of common features in the structure of needles (long, but short needles with one stomatal band and large resin passages), allowing to consider them a typical form of J. communis var. saxatilis. The North American population does not differ from the far Eastern populations in all studied features and is most likely an American form of J. communis var. saxatilis. Siberian and European populations make up a single group, where each population shows features as J. communis var. saxatilis and J. communis var. communis. The exceptions are the Tallinn and Tomsk populations, characterized by long and narrow needles and tree life form, and probably is a typical form of juniper - J. communis var. communis. The most valuable features for the purposes separation of taxa are the length and width of needles, the number of bands and Ka, anatomical features were less valuable.

Key words. Intraspecific taxonomy, Juniper common, morphology, anatomy, variability.

Можжевельник обыкновенный (J. communis L.) - вечнозеленый хвойный вид из семейства кипарисовых, произрастающий на территории Северного полушария. В силу высокой пластичности, вид 
представлен большим числом форм и разновидностей и имеет запутанную и часто спорную таксономию (Farjon, 2001; Adams, 2014). Основными признаками для выделения синтаксонов являются форма роста и параметры хвои. A. Farjon (2001) выделяет в Евразии две разновидности можжевельника обыкновенного: J. communis L. var. communis (форма прямостоячего куста) и J. communis var. saxatilis Pall. (форма стланика). Обе разновидности имеют сходные морфологические признаки и перекрывающийся ареал на территории России, охватывающий европейскую часть России, Урал, Сибирь, и до сих пор так и не выяснено, чем еще кроме разной жизненной формы (прямостоячего куста и стланика) и разных условий произрастания отличаются эти две разновидности.

Еще одна разновидность можжевельника обыкновенного - J. communis var. oblonga hort. ex Loudon. (= J. oblonga M.-Bieb., J. albanica Penzes, J. communis var. caucasica Endl., J. communis var. saxatilis Pall.) произрастает на Кавказе (Галушко, 1978; Джанаева, 1969; Черепанов, 1995) и имеет достаточно четкие анатомо-морфологические отличия. A. Farjon (2001) не признает выделения этого можжевельника даже в качестве разновидности. В то же время он выделяет в качестве отдельной североамериканской разновидности J. communis var. depressa, внешне очень похожий на J. communis var. saxatilis.

Многие исследователи отмечают высокую пластичность анатомо-морфологических признаков хвои можжевельников (Долгая, 1937, Нестерович и др., 1986, Герлинг, 2011). Являясь самым чувствительным органом, хвоя реагирует на изменения окружающей среды и определяет развитие других органов растения (Правдин, 1964). Изучение ее изменчивости позволяет понять адаптационные перестройки вида и направления его микроэволюции (Нестерович и др., 1986).

Нами проводилось исследование анатомо-морфологической изменчивости параметров хвои (длина хвои, ширина хвои, длина кончика хвои, высота и толщина среза, периметр и площадь среза, периметр и площадь смоляного хода и проводящего пучка, ширина устьичной полоски, число устьичных полосок, толщина покровных тканей, число устьиц и их размеры, число обкладочных клеток, коэффициент Адамса, высота, ширина и форма киля) 25 природных популяций Juniperus communis L., произрастающих на территории Европы, Азии и Северной Америки (табл.).

Таблица

Исследуемые популяции Juniperus communis

\begin{tabular}{|c|c|c|c|c|}
\hline № & Популяция & Широта & Долгота & $\begin{array}{c}\text { Высота } \\
\text { над у. м (m) }\end{array}$ \\
\hline $\mathrm{J} 1$ & Альпы (Сев.Тироль) & $\mathrm{N} 47^{\circ} 11^{\prime}$ & $\mathrm{E} 12^{\circ} 0^{\prime}$ & 1700 \\
\hline $\mathrm{J} 2$ & Эстония (окр. Таллина) & N $57^{\circ} 27^{\prime}$ & E $24^{\circ} 52^{\prime}$ & 22 \\
\hline $\mathrm{J} 3$ & Таганай (Южный Урал) & $\mathrm{N} 55^{\circ} 10^{\prime}$ & E $59^{\circ} 40^{\prime}$ & 1000 \\
\hline $\mathrm{J} 4$ & Машак (Южный Урал) & N $54^{\circ} 19^{\prime}$ & E $58^{\circ} 06^{\prime}$ & 669 \\
\hline J5 & Полярный Урал & $\mathrm{N} 66^{\circ} 50^{\prime}$ & E $65^{\circ} 40^{\prime}$ & 250 \\
\hline J6 & Туруханск (Вост. Сибирь) & $\mathrm{N} 65^{\circ} 48^{\prime}$ & E $87^{\circ} 59^{\prime}$ & 40 \\
\hline $\mathrm{J} 7$ & Томск & N $56^{\circ} 70^{\prime}$ & E $84^{\circ} 76^{\prime}$ & 133 \\
\hline $\mathrm{J} 8$ & Ергаки (Южная Сибирь) & N $53^{\circ} 08^{\prime}$ & E $92^{\circ} 56^{\prime}$ & 1750 \\
\hline J9 & Горная Шория (Юж. Сибирь) & N $52^{\circ} 55^{\prime}$ & E $88^{\circ} 00^{\prime}$ & 1570 \\
\hline $\mathrm{J} 10$ & Тянь-Шань & $\mathrm{N} 43^{\circ} 06^{\prime}$ & E $77^{\circ} 04^{\prime}$ & 3000 \\
\hline $\mathrm{J} 11$ & Северобайкальск & N $55^{\circ} 42^{\prime}$ & E $109^{\circ} 04^{\prime}$ & 536 \\
\hline $\mathrm{J} 12$ & Газимур & $\mathrm{N} 52^{\circ} 09^{\prime}$ & E $119^{\circ} 2^{\prime}$ & 936 \\
\hline $\mathrm{J} 13$ & Лазо (Приморье) & $\mathrm{N} 43^{\circ} 31^{\prime}$ & E $134^{\circ} 06^{\prime}$ & 1287 \\
\hline $\mathrm{J} 14$ & Сихотэ-Алинь (Приморье) & $\mathrm{N} 45^{\circ} 00^{\prime}$ & E $136^{\circ} 30^{\prime}$ & 842 \\
\hline $\mathrm{J} 15$ & Якутия & $\mathrm{N} 63^{\circ} 28^{\prime}$ & E $120^{\circ} 3^{\prime}$ & 120 \\
\hline $\mathrm{J} 16$ & Колыма (северо-восток) & $\mathrm{N} 63^{\circ} 25^{\prime}$ & E $140^{\circ} 36^{\prime}$ & 120 \\
\hline $\mathrm{J} 17$ & Магадан (северо-восток) & N 593' & E $150^{\circ} 4^{\prime}$ & 118 \\
\hline $\mathrm{J} 18$ & Камчатка (северо-восток) & $\mathrm{N} 56^{\circ} 01^{\prime}$ & E $161^{\circ} 11^{\prime}$ & 50 \\
\hline $\mathrm{J} 19$ & Аляска (Сев. Америка) & N $64^{\circ} 50^{\prime}$ & $\mathrm{E}-147^{\circ} 4^{\prime}$ & 135 \\
\hline $\mathrm{J} 20$ & Ногайская степь (Дагестан) & $\mathrm{N} 44^{\circ} 04^{\prime}$ & E $45^{\circ} 35^{\prime}$ & 60 \\
\hline
\end{tabular}


«Проблемы ботаники Южной Сибири и Монголии» - XVIII Международная научно-практическая конференция

Таблица (окончание)

\begin{tabular}{|c|c|c|c|c|}
\hline № & Популяция & Широта & Долгота & $\begin{array}{c}\text { Высота } \\
\text { над у. м (m) }\end{array}$ \\
\hline $\mathrm{J} 21$ & Сочи & $\mathrm{N} 43^{\circ} 42^{\prime}$ & $\mathrm{E} 40^{\circ} 10^{\prime}$ & 1000 \\
\hline $\mathrm{J} 22$ & Архыз (Карачаево-Черкесия) & $\mathrm{N} 43^{\circ} 34^{\prime}$ & E $41^{\circ} 16$ & 2034 \\
\hline $\mathrm{J} 23$ & Нальчик (Сев. Осетия) & $\mathrm{N} 43^{\circ} 08^{\prime}$ & E $43^{\circ} 29^{\prime}$ & 1470 \\
\hline $\mathrm{J} 24$ & Гуниб (Дагестан) & $\mathrm{N} 42^{\circ} 24^{\prime}$ & E $46^{\circ} 54^{\prime}$ & 1850 \\
\hline $\mathrm{J} 25$ & Талги (Дагестан) & $\mathrm{N} 42^{\circ} 62^{\prime}$ & $\mathrm{E} 47^{\circ} 26^{\prime}$ & 458 \\
\hline
\end{tabular}

Кавказские популяции резко отличаются от остальных по большинству изученных параметров хвои (рис. 1-4). Самая длинная хвоя наблюдается у можжевельника из Ногайской степи - 22 см, самая широкая - у растений из Гунибского плато - 2, 3 см. Полученные данные подтверждают правомерность выделения кавказских можжевельников в отдельную группу, а наличие четкого хиатуса может говорить о высоком таксономическом ранге группы.

В то же время группа кавказских популяций очень неоднородная и имеет высокий уровень межпопуляционной изменчивости. Сочинская популяция среди кавказских по ряду признаков близка скорее к альпийскому можжевельнику. Растения с плато Гуниб оказались уникальными, значимо отличаясь по многим признакам от всех других популяций.

Остальные популяции по многим признакам образуют единое облако и не разделяются на группы. В то же время дальневосточные популяции характеризуются более длинной, но узкой хвоей, а европейско-сибирские - более короткой, но широкой. Таллинская популяция отличается от всех, имея длинную, но узкую хвою, и сближается по этим признакам с Томской.

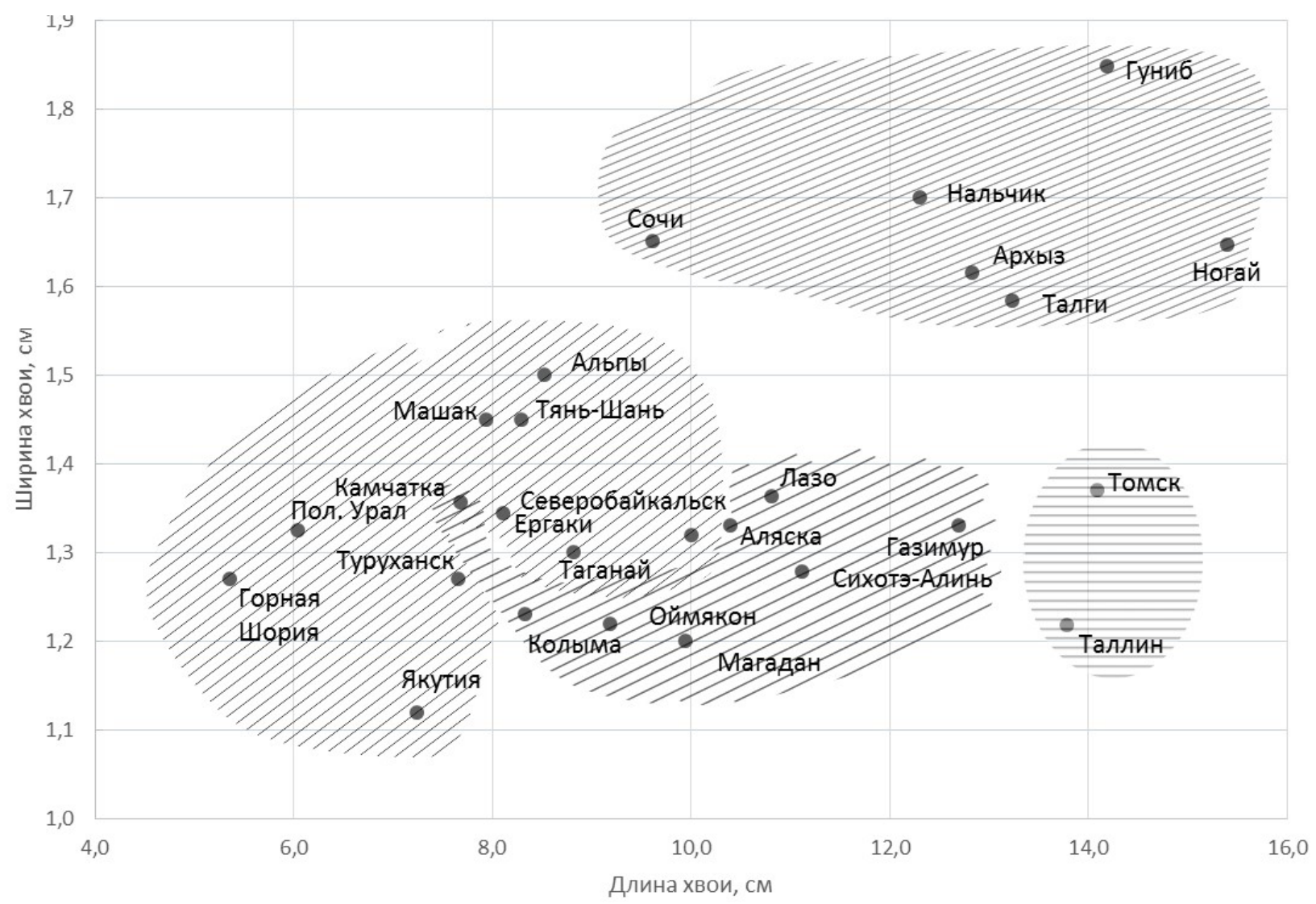

Рис. 1. Распределение популяций можжевельника в зависимости от длины и ширины хвои. 


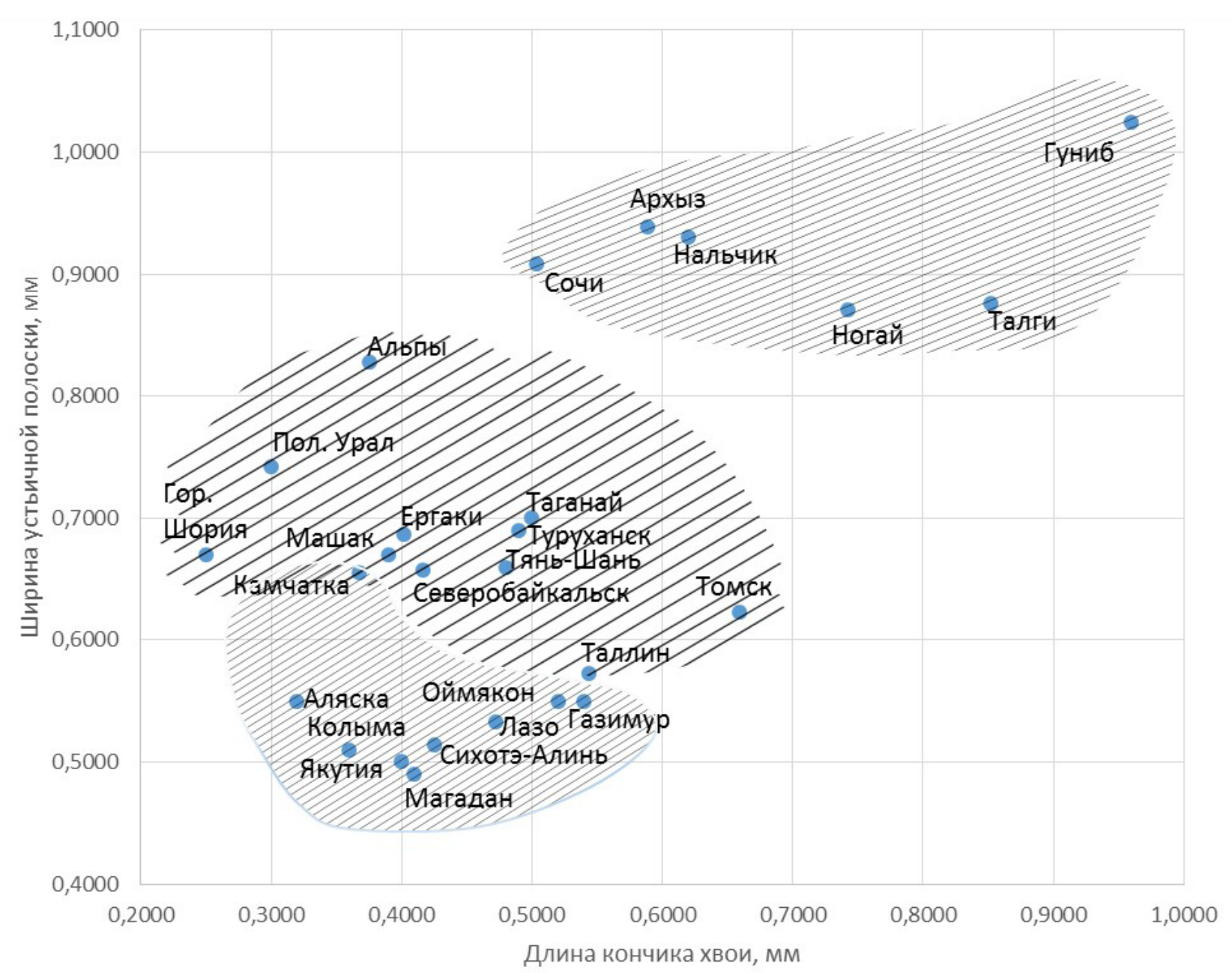

Рис. 2. Распределение популяций можжевельника в зависимости от длины кончика хвои и ширины устьичной полоски.

По другим признакам наблюдаются сходные закономерности. Так, например, кавказские растения характеризуются широкими устьичными полосками и остроконечными хвоинками (рис. 2), дальневосточные имеют самые узкие устьичные полоски, европейско-сибирские занимают промежуточное положение. Значения длины кончика у обеих групп изменяется в одинаковых пределах. Гунибский можжевельник имеет хвою с самой широкой устьичной полоской и самым длинным кончиком. Североамериканская популяция по изученным признакам не отличается от дальневосточных популяций.

Анатомические параметры кавказских популяций также четко отделяются от всех остальных популяций и характеризуются крупными проводящими пучками, но небольшими смоляными ходами (рис. 3). Дальневосточные популяции, наоборот, имеют крупные смоляные ходы, но небольшие проводящие пучки. Европейско-сибирские характеризуются, как правило, мелкими проводящими пучками и смоляными ходами. Тем не менее отделить две последние группы друг от друга невозможно.

По числу обкладочных клеток очень сильно отличаются популяции из Гуниба, Талги и Нальчика, которые имеют более 10 обкладочных клеток. Остальные кавказские популяции также содержат повышенное (более 5) число обкладочных клеток по сравнению с остальными популяциями, где это число не превышает трех.

В систематике можжевельников также используют такие признаки, как число полосок и отношение длины устьичной полоски к зеленым концам хвои (коэффициент Адамса - Ка) (Adams, 2008, Джанаева, 1969). По данным признакам значительно отличаются кавказские популяции (рис. 4). У большинства растений наблюдается две устьичные полоски и коэффициент Адамса имеет значение 


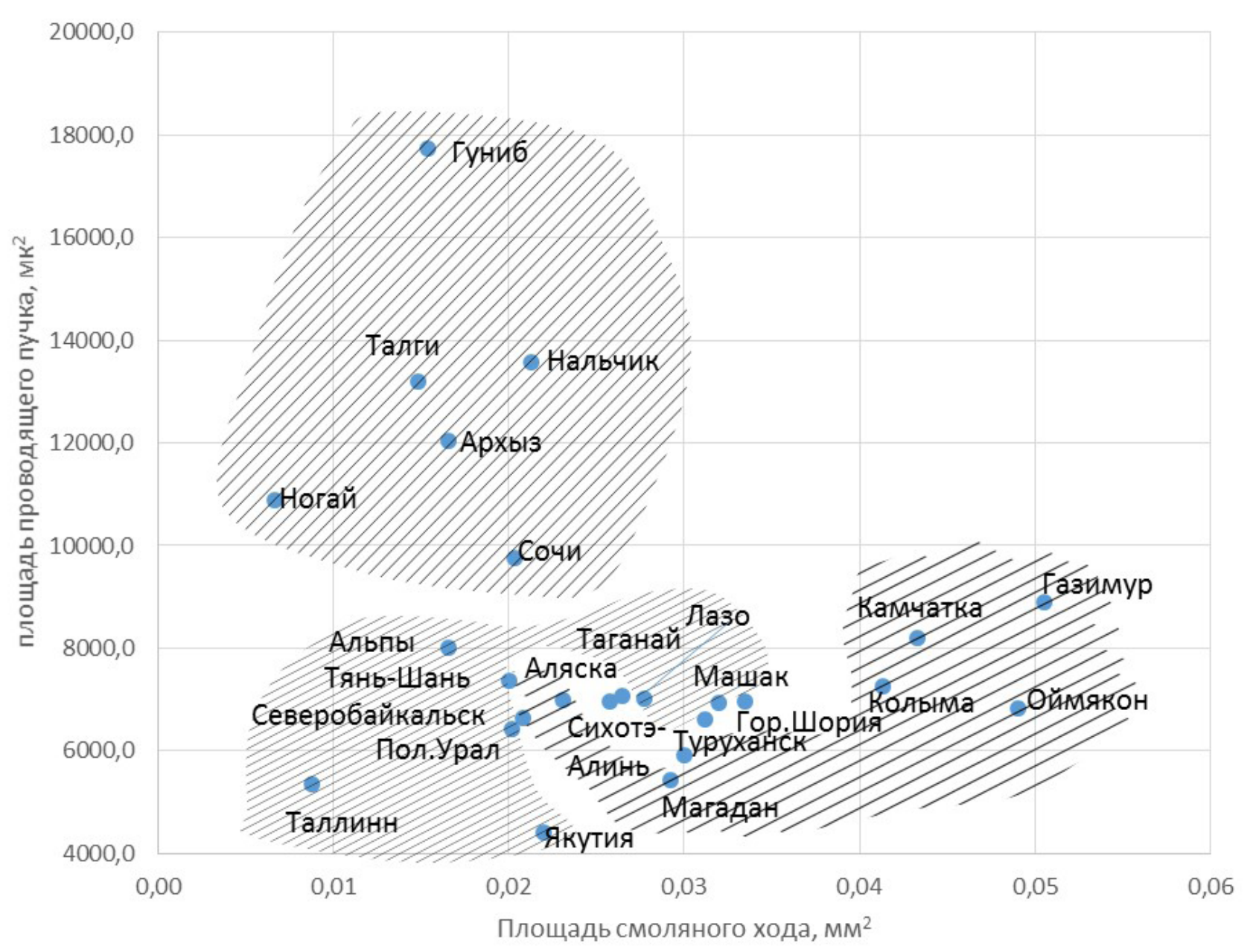

Рис. 3. Распределение популяций в зависимости от площади смоляного хода и проводящего пучка.

больше 2. Большинство дальневосточных популяций характеризуются одной устьичной полоской и Ка, как правило, меньше 1,5. Широкая европейско-сибирская зона занимает обширное промежуточное положение.

Таким образом, исследование анатомо-морфологической изменчивости показало, что кавказские популяции по всем признакам отличаются от остальных и, вероятно, кавказский можжевельник представляет собой отдельный вид или разновидность. Кавказский можжевельник отличается широкой и длиной хвоей, развитым проводящим пучком с большим количеством обкладочных клеток, крупным поперечным срезом, длинным кончиком хвои, широкой устьичной полоской с двумя полосками и Ка > 2. Переходной оказалась популяция из Сочи, которая по ряду параметров близка к альпийским растениям, относящимся к J. communis var. saxatilis.

Дальневосточные популяции характеризуются рядом общих черт в строении хвои (длинная, но короткая хвоя с одной устьичной полосой и крупными смоляными ходами), позволяющих считать их типичной формой $J$. communis var. saxatilis. В то же время растения из Камчатки, Оймякона и Газимура по некоторым признакам оказались близки к сибирским. Североамериканская популяция объединилась с дальневосточными популяциями и скорее всего является американской формой J. communis var. saxatilis.

Сибирские и европейские популяции составляют единую группу, где у каждой популяции в разной степени проявляются признаки как J. communis var. saxatilis, так и J. communis var. communis. Исключением являются Таллинская и Томская популяции, отличающиеся длинной и узкой хвоей и мелкими проводящими пучками и смоляными ходами и, вероятно, являющиеся типичной формой можжевельника обыкновенного - J. communis var. communis. 


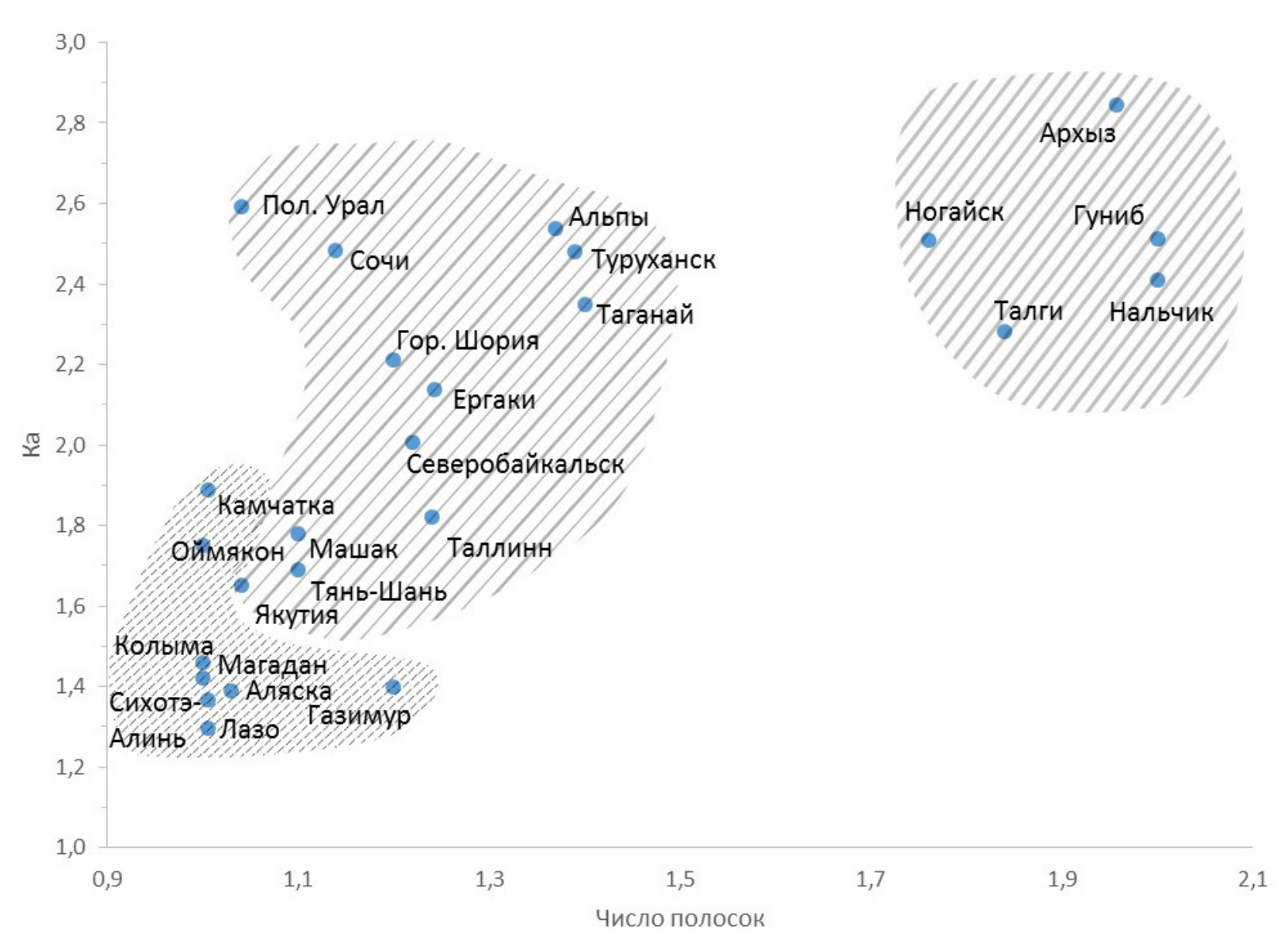

Рис. 4. Распределение популяций можжевельника в зависимости от числа полосок и Ка.

Наиболее ценными признаками для целей разделения таксонов являются длина и ширина хвои, число полосок и Ка, анатомические признаки оказались менее информативными.

\section{ЛИТЕРАТУРА}

Галуико А. И. Флора Северного Кавказа. - Изд-во Рост. ун-та, 1978. - 318 с.

Герлинг Н. B. Структура хвои видов р. Juniperus в условиях интродукции в среднетаежной подзоне Республики Коми // Ботанические сады в современном мире: теоретические и прикладные исследования: Матер. всеросс. научн. конф. с междунар. участием, посвящ. 80-летию со дня рождения академика Л. Н. Андреева. - М.: Товарищество научных изданий КМК, 2011. - С. 11-116.

Джсанаева В. М. Определитель семейства можжевеловых. - Изд-во: Илим, Фрунзе, 1969. - 93 с.

Долгая К. 3. Влияние климата на анатомо-морфологические особенности хвои можжевельников // Труды ленинградского общества естествоиспытателей, 1937. - Вып. 2, T. LXVI. - С. 249-295.

Нестерович Н. Д., Дерюгина Т. Ф., Лучков А. И. Структурные особенности листьев хвойных. - Минск: Наука и техника, 1986. -143 с.

Правдин Л. Ф. Сосна обыкновенная. - М.: Наука, 1964. - 191 с.

Черепанов С. К. Сосудистые растения России и сопредельных государств. - С-Пб: Мир и семья, 1995. - 990 с.

Farjon A. World checklist and bibliography of conifers. - England: The Royal Botanic Gardens, 2001. -309 p.

Adams R. P. Juniperus of Canada and United Stayes: taxonomy, key and distribution // Phytologia, 2008. - № 90 (3). - P. 255-314.

Adams R. P. Junipers of the World: The genus Juniperus. -4 th edn. - Trafford Publishing, 2014. -422 p. 